\title{
CONCEPÇÃO POLÍTICA E HISTÓRICA DA FORMAÇÃO DA EDUCAÇÃO SUPERIOR NO BRASIL: DA ORIGEM AOS DIAS ATUAIS
}

\author{
POLITICAL AND HISTORICAL CONCEPTION OF THE FORMATION OF \\ SUPERIOR EDUCATION IN BRAZIL: FROM THE ORIGINS TO CURRENT \\ DAYS.
}

\author{
Armindo Quillici Neto ${ }^{1}$
}

\begin{abstract}
RESUMO
O texto trata do desvelamento da concepção política que sustentou a implantação e desenvolvimento da Educação Superior no Brasil, desde a vinda da Família Real até o período contemporâneo. A questão que norteia o texto tenta identificar qual concepção foi vigente na constituição da Educação Superior brasileira. O artigo aponta, ainda, que a necessidade da Educação Superior se deu diante da vinda da Família Real, uma vez que o país não dispunha de infraestrutura básica para o fornecimento de serviços que atendiam ao sistema que estava sendo implantado. Sendo assim, o século XIX assistiu a influências de algumas correntes de pensamento que já eram vigentes na Europa. O país recebeu influência de concepções fundadas no Ecletismo, que, por sua vez, tinha raízes no Naturalismo e no Liberalismo Político. No período da República, principalmente nas primeiras décadas, buscou-se demonstrar a presença forte do Liberalismo e, sobretudo, a implantação dos ideais do Positivismo. Esses ideais foram marcantes para o desenvolvimento dos novos projetos de educação que o país buscou implantar após o rompimento com a educação da Igreja católica. Em meio ao espírito de mudanças, educadores lutavam por uma educação leiga, em que o Estado respondesse pela responsabilidade da educação. Por meio de análise histórica e política da educação, localiza-se a legislação que deu sustento à formação das escolas superiores, principalmente a Reforma Francisco Campos, a Reforma Universitária, de número 5.540/68, a Lei de Diretrizes e Bases da Educação Nacional, de número 9.394/96, e o Plano Nacional de Educação, aprovado pela Lei no .10 .172 , em 09 de janeiro de 2001. Os autores que sustentaram a referida reflexão foram: ANTUNHA (1975), AZEVEDO (1971), BRZEZINSKI (1996), CUNHA (1986), CURY (1978), FAORO (1958), FÁVERO (1998), FIGUEIREDO (2005), FRANCA (1952), LAUWERYS (1969), LEITE (1989), NAGLE (1976), PAIM (1974), SCHWARTZMAN (2005), e outros.
\end{abstract}

Palavras-chave: História. Concepção. Política. Educação Superior.

\footnotetext{
${ }^{1}$ Professor adjunto da Universidade Federal de Uberlândia - UFU. E-mail: armindo@pontal.ufu.br
} 


\begin{abstract}
This article discusses the political concept that supported the implementation and development of Higher Education in Brazil since the arrival of the Royal Family up to contemporary days. The aim of the article is to identify the conception that guided the creation of Brazilian Higher Education. Moreover, the article points out that the implementation of Higher Education in Brazil coincides with the arrival of the Royal Family as the country did not have the basic infra-structure to offer the services necessary to the system that was being implemented. The $19^{\text {th }}$ century saw the political and philosophical ideologies spread across Europe. The country suffered influences based on Eclecticism which was influenced by Naturalism and Political Liberalism. During the first decades of the Republic, Liberalism was strong and the ideals of Positivism were being implemented. Those ideals were very important to the development of the new projects of education that the country tried to implement after the break up with the Catholic Church. With so many changes taking place, educators fought to make education a simple act provided by the Estate. The historical and political analysis of education demonstrates the legislation that oriented the creation of Higher Education, in particular the "Francisco Campos Reform", "University Reform" 5.540/68, the "Guidelines ad Basis for National Education Law" 9.394/96 and the "National Education Plan" approved by Law 10.172 of January, $9^{\text {th }} 2001$. The authors that supported this analysis were: AZEVEDO (1971), ANTUNHA (1975), BRZEZINSKI (1996), CUNHA (1986), CURY (1978), FAORO (1958), FÁVERO (1998), FIGUEIREDO (2005), FRANCA (1952), LAUWERYS (1969), LEITE (1989), NAGLE (1976), PAIM (1974), SCHWARTZMAN (2005), and others.
\end{abstract}

Keywords: History. Conception. Politics. Higher Education.

\section{Introdução}

O texto que ora apresentamos é resultado de um estudo sobre as concepções políticas que sustentaram a elaboração legal da Educação Superior no Brasil desde o Império até o período contemporâneo. Trata-se de uma reflexão filosófica que tenta identificar quais ideais foram hegemônicos na constituição dos cursos superiores.

Quanto ao período do Império, buscou-se apontar que a necessidade da Educação Superior se deu diante da vinda da Família Real, uma vez que o país não dispunha de infraestrutura básica para o fornecimento de serviços que atendiam ao sistema que estava sendo implantado. Sendo assim, o século XIX assistiu a influências de algumas correntes de pensamento que já eram vigentes na Europa. O país recebeu influência de concepções fundadas no Ecletismo, que, por sua vez, tinha raízes no Naturalismo e no Liberalismo Político.

No período da República, principalmente nas primeiras décadas, buscou-se demonstrar a presença forte do Liberalismo e, sobretudo, a implantação dos ideais do Positivismo. Esses ideais foram marcantes para o desenvolvimento dos novos projetos de educação que o país buscou implantar após o rompimento com a educação da Igreja católica. Em meio ao espírito de mudanças, educadores lutavam por uma educação leiga, em que o Estado respondesse pela responsabilidade da educação. O marco importante da época foi o "Manifesto do Pioneiro da Escola Nova", em 1932, e o surgimento da universidade brasileira por meio da Reforma Francisco Campos.

O texto aponta, ainda, o significado da Lei da Reforma Universitária, de 1968, que surge no bojo do Regime Militar, momento em que a industrialização ia ganhando forças na economia. O modelo de Ensino Superior que se implantou a partir da década de 1960 foi o que mais se aproximou dos interesses do norte da América. O país estabeleceu o convênio MEC-USAID, que se tratava de um acordo de cooperação, e recebeu apoio técnico para a reformulação de seu sistema de educação.

A publicação da Lei de Diretrizes e Bases da Educação Nacional, de número 9.394, de 1996, e a aprovação do Plano Nacional de Educação, em 2001, 
significaram uma nova postura sobre a Educação Superior nos últimos dez anos. O texto busca refletir sobre as consequências da expansão da Educação Superior provocadas pela nova legislação e a questão do acesso das classes menos favorecidas nos bancos universitários.

\section{Da concepção sobre a formação do Ensino Superior no Brasil}

\subsection{Do Império}

A abertura de cursos superiores no Brasil se deu após a chegada da Família Real em 1808, no período em que se instalou no Rio de Janeiro o sistema administrativo da coroa. A abertura de tais cursos se justifica porque as necessidades do sistema que estava sendo implantado tinham que ser atendidas. Sendo assim, ocorreram mudanças significativas, tanto no plano econômico e político, como também, e principalmente, no da educação. Especificamente durante a segunda metade do século XIX, com o impulso da criação dos cursos superiores que preparavam a elite intelectual de jovens para o poder, surgiu uma corrente de pensamento que proclamava o fim da Escolástica e cultuava a abertura em relação ao pensamento moderno.

Embora estudiosos da época evidenciem que, principalmente na primeira metade do século XIX, não havia o menor indício de uma consciência filosófica configurada, o Brasil recebeu a influência denominada de Ecletismo. Essa concepção, fundada no

naturalismo, no liberalismo econômico, cujos adeptos adquirem influência crescente na esfera política - não desembocava em movimento filosófico, digamos, nos moldes do empirismo inglês". “(...) Ao mesmo tempo, a receptividade às idéias ético-políticas trazidas à baila pelas revoluções Americana e Francesa não chega a adquirir maior consistência. Pelo menos não desemboca em qualquer corrente de opinião proeminente e destacada. (PAIM, 1974, p. 180).

Um importante pensador que aderiu à corrente do ecletismo esclarecido foi Silvestre Pinheiro Ferreira (1769 - 1846), "que se incumbiria de preparar os espiritos na busca de conteúdo para aquela doutrina que o Visconde de Uruguai denominaria de 'ecletismo esclarecido'(...)". (PAIM, 1974, p. 180).
Professor da cadeira de Filosofia Racional e Moral do Colégio das Artes de Coimbra, Silvestre Pinheiro Ferreira viveu sete anos na Alemanha (1802 - 1809), onde acompanhou de perto a evolução do Kantismo, tendo assistido às conferências de Fichte e Schelling. Veio ao Brasil em 1809, permanecendo no país até 1821 .

No Brasil, o referido pensador ministrou um curso de filosofia no Real Colégio de S. Joaquim, antigo seminário.

Reinterpreta Aristóteles segundo cânones empiristas e situa a Locke e Condillac como seu desdobramento natural. Pretende harmonizá-los num sistema que tenha a grandiosidade da Escolástica, preserve as conquistas de Verney e lhes assegure desenvolvimento coerente no plano ético. (PAIM, 1974, p. 181).

Nas preleções filosóficas sobre a teoria do discurso e da linguagem, a Estética, a Diceósina e a Cosmologia, denominação dada ao curso de Silvestre, apresentam as seguintes teses:

1) Os fundamentos últimos de todas as ciências repousam na experiência sensível.

2) Embora, extremamente complexo, lento e perfectível, o processo de elaboração e sistematização dos conhecimentos empíricos tem sua unidade assegurada:

a) pela identidade da razão humana; e

b) pela correspondência existente entre linguagem e realidade.

3) A filosofia é a disciplina que comanda e assegura o êxito do aludido processo.

O ecletismo teve adesão de vários estudiosos, era um novo momento do pensamento que se estabelecia a partir de novos interesses políticos, econômicos e ideológicos que sustentavam a nova ordem filosófica:

O famoso pregador Monte Alverne (1784 - 1855), do diretor da faculdade de medicina, Moraes e Vale (1824 - 1886), e de Domingos de Magalhães (1811 - 1882), figura de proa do Romantismo. A formação intelectual do jovem Tobias Barreto é toda de inspiração eclética (PAIM, 1974, p.207). Domingos de Magalhães, Eduardo Ferreira França e o Bispo do Pará, Moraes Torres (1805 - 1865). (PAIM, 1974, p. 207) ${ }^{2}$.

\footnotetext{
${ }^{2}$ Cruz COSTA, grande estudioso do pensamento brasileiro, comenta sobre Silvio Romero: "No entanto, Silvio Romero, ao publicar a filosofia no Brasil, em 1878, tentara classificar os nossos filósofos em três grupos: os escritores educados no sensualismo francês, dos primeiros anos do século XIX; os
} 
Segundo PAIM (1974), a "corrente eclética representa o primeiro movimento filosófico plenamente estruturado no Brasil". Baseado nas idéias de Victor Cousin (1792 - 1867), professor de filosofia na Escola Normal de Paris desde 1814, e por ele apresentado, esse movimento - denominado de ecletismo espiritualista - passou a ser uma espécie de filosofia oficial na França (PAIM, 1974, p. 204). Sua filosofia tem três aspectos básicos: 1) o ecletismo como método (historicismo); 2) o método psicológico, elevado à condição de fundamento último da filosofia; e 3) o espiritualismo.

A segunda metade do século XIX é considerada como o momento da ascensão do espírito crítico. Surgiram então dois movimentos extremamente complexos: a Escola de Recife e o Positivismo. Encarada como corrente filosófica, a Escola de Recife desenvolveu-se em quatro fases perfeitamente distintas, admitindo-se a existência de um primeiro ciclo, no qual seus fundadores são simples participantes do denominado surto de ideias novas.

\section{Antonio PAIM diz que:}

carece de maior significação batizar a escola de Recife de corrente evolucionista ou contentar-se com a classificação de positivismo ortodoxo e positivismo dissidente, elaborada em conformidade com o modelo francês. (PAIM, 1974, p. 258).

Vários autores atribuem a Tobias Barreto o mérito de haver aberto novos caminhos para se discutir a filosofia brasileira. Assim,

a Escola de Recife constitui aquele processo de diferenciação no seio do chamado surto de idéias novas que consiste conduzir às últimas conseqüências o rompimento com o Positivismo, trazendo à luz um grupo de problemas capazes de facultar o prosseguimento do diálogo filosófico, no qual os brasileiros, como vimos, recém haviam ingressado. Impulsiona-o Tobias Barreto. (PAIM, 1974, p. 260) ${ }^{3}$.

A influência do pensamento francês, segundo CUNHA (1986),

neocatólicos filiados às doutrinas de Rosmini e Gioberti ou a Balmes e Ventura; e afinal os que se iam emancipando, sob a tutela das idéias de Comte e de Darwin... Não reparou ele na curiosa emancipação que é aquela que se realiza sob tutela... Talvez, por isso mesmo, alterou, mais tarde, em 1905, a classificação que fizera em 1878”. (COSTA, 1967, p. 101).

${ }^{3}$ Note-se o comentário de Antonio PAIM (1974) sobre o surto de ideias novas no Brasil: "Ao que tudo indica, Silvio Romero teria sido o pensador brasileiro que mais chamou a atenção para a circunstância de que a década de 70 do século passado caracteriza-se, sobretudo, pelo fato de que "um bando de idéias novas esvoaçou sobre nós de todos os pontos do horizonte". (PAIM, 1974, p.255). chegou ao Brasil primeiro via Portugal pombalino, depois via missão artística e obras educacionais do príncipe regente, culminando, por múltiplas vias, no império, quando Aluísio de Azevedo afirmava que incontestavelmente 'a França é a sede do pensamento humano'. (...) A cultura francesa serviu admiravelmente bem para as classes dominantes locais, que primeiro no reino português, depois no império brasileiro, garantiam pelas relações comerciais, a continuação do movimento do capitalismo na Inglaterra. (CUNHA,1986, p.133).

Portanto, o ensino superior brasileiro se espelhou no movimento de mudanças para uma "nova" filosofia e uma nova ciência, ambas calcadas nos princípios de rompimento com a mentalidade implantada pela Igreja Católica desde o início da colonização. A nova ordem se justificava pela mudança de mentalidade que se multiplicava na Europa durante o século XIX. Mesmo se tratando de um momento em que havia um surto de novos ideais, o ensino superior brasileiro, no século XIX, não se realizou satisfatoriamente, o número de cursos foi insuficiente para atender à demanda do Império.

\subsection{Da República}

A República, proclamada em 1889, que, por um lado, trazia o espírito dos ideais de mudanças, de rompimento com o antigo regime e com a Igreja, e, por outro, tratava da implantação de um sistema que atendia aos interesses da camada média e dos senhores do café, que viam nela a possibilidade de novos lucros, era sustentada pelo ideal do Liberalismo político. Segundo Faoro (1976), o Liberalismo foi sustento para as novas ideias do capitalismo que surgia no Brasil. Essa ideologia

articula-se aos padrões universais, irradiados da Inglaterra, França e Estados Unidos, confortando a consciência dos ocidentalizadores, modernizadores da sociedade e da política brasileiras, muitas vezes enganados com a devoção sem exames aos modelos. (FAORO, 1976, p.501).

O Positivismo, filosofia que marcou profundamente os ideais da política brasileira dessa época, influenciou de forma também marcante a reforma de ensino de Benjamim Constant, nomeado primeiro Ministro da Instrução, Correios e Telégrafos (de 1890 a 1892). Tal reforma atingiu diretamente as Faculdades de Direito e de Medicina, e a Escola Politécnica, do 
Rio de Janeiro; a Escola de Minas, de Ouro Preto, e a Escola Militar; a Academia de Belas Artes, que tomou o nome de Escola Nacional de Belas Artes; o Conservatório de Música, que passou a chamar-se Instituto Nacional de Música; o Imperial Instituto de Meninos Cegos, denominado então Benjamin Constant; e o Instituto de Surdos-Mudos. O Positivismo sustentou a ideologia da mudança e a crença no progresso do capitalismo.

Fernando de Azevedo (1971) traz algumas informações importantes sobre a situação do ensino após a Constituição de 24 de fevereiro de 1891:

Além de instituir a forma federativa, transfere a instrução primária aos Estados, a instrução secundária e superior também foi reservada aos Estados, mas não privativamente, foi posta diretamente sob a jurisdição do governo central.

Num comentário de rodapé, Azevedo apresenta as principais indicações dessa Constituição:

Assegurava à união competência para legislar sobre o ensino superior da capital da República (art. 35, $n^{0} 30$ ) e lhe dava, não privativamente, atribuição de criar instituições de ensino superior nos Estados e prover à instrução no Distrito Federal (art. 35, ns. 3 e 4). Estabelecia ainda a laicidade do ensino administrado nos estabelecimentos públicos (art. 72, $n^{\circ} 6$ ) e garantia, no parágrafo 24 do art. 72 , 'o livre exercício de qualquer profissão moral, intelectual e industrial'. Por essas poucas disposições, esparsas na Constituição de 91, ficam repartidas da seguinte forma as atribuições do governo da união e dos governos estaduais: a) à União competia privativamente legislar sobre o ensino superior na capital da República, cabendo-lhe, mas não privativamente, criar instituições de ensino secundário e superior nos Estados e prover à instrução no Distrito Federal; b) aos Estados se permitia organizar os seus sistemas escolares completos; c) no Distrito Federal, pertencia o ensino superior à alçada do governo do país, a que se facultava, mas não se impunha, prover à instrução nos graus primário e médio. Donde se seguia a possibilidade de organização, simultânea e paralela, de três tipos de sistemas escolares: a) o sistema escolar federal, constituído, no território do país, do ensino secundário e superior, e necessariamente incompleto: b) sistemas escolares estaduais completos; c) e dois tipos de organizações escolares públicas no distrito federal: uma, dos poderes municipais, sem o ensino superior, e outra, da União, que tinha o direito exclusivo de legislar sobre o ensino superior e a faculdade organizar, no Distrito Federal, a instrução em todos os graus (...). (AZEVEDO, 1976, p. 619).

Outro dado importante, ocorrido na Constituição republicana de 1891, foi a separação da Igreja em relação ao Estado, ou seja, a laicização do ensino dos estabelecimentos públicos (art. 72, $\mathrm{n}^{\circ} 6$, da Constituição de 1891). Cury (1978), estudioso da questão acima citada, quando trata da relação entre ideologia Católica e ideologia Liberal, aponta para o indício do rompimento da visão Liberal com a visão Católica, ou seja,

a República rompe oficialmente com o Padroado e se proclama leiga. O rompimento desta simbiose não significou um abalo muito profundo nas relações entre ambos os poderes. O Padroado não permitia uma margem muito grande de atuação por parte da Igreja. Já a separação oficial permite que a Igreja Católica reestruture na área religiosa os quadros eclesiásticos, seja na sua formação, seja na sua ampliação e mesmo moralização. Os laços com a Sé romana começaram se tornar mais e mais fortes. (CURY, 1978, p.14).

No final do século XIX, com todo espírito de mudanças, a Igreja já não dispunha de um clero com bastante influência nas consciências e força na sociedade, capaz de desencadear uma reação eficaz e de grande envergadura. Dentro do novo regime em que o Estado instituiu o sistema de neutralidade escolar ${ }^{4}$ e influência da iniciativa privada sob o impulso de diversas ordens religiosas, nenhuma ainda chegava a disputar a primazia da Igreja. Foi nesse espírito de liberdade de pensamento e de crenças que tivemos uma influência bastante significativa do protestantismo.

Segundo Azevedo (1976),

as escolas protestantes tiveram, no regime republicano, rápidos progressos que lhe abriram, na história da Educação do país, não só um lugar indisputável, mas uma fase fecunda de atividades renovadoras. Foi em grande parte através das escolas, sob influência direta de ministros e educadores protestantes da América do Norte, que se processou no Brasil a propagação inicial das idéias pedagógicas americanas que começaram a irradiar-se em São Paulo, Rio de Janeiro e Minas Gerais. (AZEVEDO, 1976, p.628)

\footnotetext{
${ }^{4}$ Significava a tentativa de romper com a Educação da Igreja Católica.

${ }^{5}$ Em Sã o Paulo a influência americana se deu com a fundação da Escola Americana em 1871 e do Colégio Piracicabano em 1881. Esta influência atingiu também a reforma de Leôncio de Carvalho (1878-79), o parecer de
} 
As escolas protestantes, diante das inovações da técnica pedagógica norte-americana, lutaram para renovar os processos didáticos do ensino no Brasil. Foi mais um momento de empenho para superar a visão de homem, mundo e Educação trazida pelos jesuítas. Azevedo (1976) mostra que

fundadas sobretudo pelas Igrejas Metodista e Presbiteriana, essas muitas outras escolas filiadas às diversas correntes protestantes, trouxeram uma contribuição ponderável à Educação feminina; introduziram a coeducação dos sexos, estabelecendo classes mistas desde 1871, em todos os cursos do Mackenzie e em outros institutos. (AZEVEDO, 1976, p.629).

Quanto às escolas superiores criadas a partir da Proclamação da República, Cunha levanta o ano de criação das mesmas:

Direito: 1891 - Faculdade Livre de Ciências Jurídicas e Sociais do Rio de Janeiro. Em nota de rodapé, o autor faz o seguinte comentário: incentivado pela reforma parcialmente frustrada de Leôncio de Carvalho, Fernando Mendes de Almeida tentou criar uma faculdade livre de Direito no Rio de Janeiro. Em 18 de abril de 1882 fundou, com um grupo de amigos, essa faculdade, a qual não passou da ata. "Foi só em 1891, após a reforma de Benjamin Constant, que a iniciativa teve êxito". - Faculdade Livre de Direito do Rio de Janeiro. Essa faculdade resultou da iniciativa de Carlos Antonio França de Carvalho, irmão de Leôncio de Carvalho. Com o apoio dos monges beneditinos, foi criada, em 31 de maio de 1891, a Faculdade Livre de Direito; - Faculdade Livre de Direito da Bahia; - Faculdade de Direito de Goiás. 1893 - Faculdade Livre de Direito do Estado de Minas Gerais (Ouro Preto); 1903 - Faculdade Livre de Direito do Pará e Faculdade Livre de Direito de Porto Alegre; 1907 - Faculdade Livre de Direito de Fortaleza. Medicina, Obstetrícia, Farmácia, Odontologia: 1889 - Faculdade de Medicina e Farmácia de Porto Alegre; 1898 - Faculdade de Odontologia de Porto Alegre; 1902 - Faculdade de Farmácia de Pernambuco; 1904 - Escola de Farmácia do Pará; Faculdade de Farmácia e Odontologia de Juiz de Fora; 1905 - Escola Livre de Odontologia do Rio de Janeiro; Escola de Farmácia, Odontologia e Obstetrícia de São Paulo; Escola de Farmácia e Odontologia do Instituto Granbery (Juiz de Fora);

Rui Barbosa (1882-83) e o movimento de reforma de Caetano de Campos, Cesário Mota e Gabriel Prestes (1891-95). Em Minas Gerais, o Colégio Granbery, fundado em Juiz de Fora, em 1889 (AZEVEDO, 1976, p.628).
1908 - Faculdade de Odontologia de Minas Gerais. Engenharia: 1896 - Escola de Engenharia de Porto Alegre; Escola Politécnica da Bahia; 1900 - Escola Politécnica de São Paulo; 1905 - Escola Livre de Engenharia de Pernambuco. Ciências Econômicas: 1905 - Faculdade de Ciências Políticas e Econômicas do Rio de Janeiro; Faculdade de Ciências Econômicas da Bahia; 1910 - Faculdade de Ciências Econômicas do Rio Grande do Sul. Agronomia: 1900 - Escola Superior de Agricultura de Piracicaba (São Paulo); 1908 - Escola Superior de Agricultura de Lavras (Minas Gerais); 1910 - Escola Nacional de Agronomia (Rio de Janeiro) (CUNHA, 1986, 175-177)6.

Assim, as três primeiras décadas da República foram fecundas no pluralismo das ideias; embora com uma presença muito tímida, o Socialismo, o Anarquismo e o Marxismo tiveram uma condição mais reivindicatória do que de pensamento estruturado. A importância desses movimentos se refletia nas greves, nas comemorações operárias, nos comícios - ocorrências que, mais do que qualquer outro dado, constituem os elementos que importam para a história do período (NAGLE, 1976, p. 35).

O pluralismo de ideias que pipocou pelo país se sustentava também pelo avanço do capitalismo industrial que mais tarde provocava expulsão do homem do campo, obrigando-o a trabalhar nas indústrias estatais e privadas que aqui se instalavam. A primeira metade do século XX também foi palco para que se buscasse uma nova educação, não mais fundada nos princípios do catolicismo, mas uma escola pública, laica e gratuita, conforme desejavam os Pioneiros da Escola Nova. No entanto, a Igreja ainda manteve seu domínio em muitos colégios, domínio esse que perdura até hoje.

\footnotetext{
${ }^{6}$ Às duas faculdades de direito, criadas em 1827, acrescentaram-se, a partir de 1891, mais dezessete instituições de ensino jurídico, das quais somente três são posteriores a 1930; às duas antigas faculdades de medicina, cujas origens remontam aos cursos médico-jurídicos criados no tempo de D. João VI, juntaram-se novas escolas desse tipo, perfazendo um total de onze, em 1940; e oito escolas de engenharia reuniram-se, de 1891 a 1914, às duas que nos legou o regime imperial,- A Escola Politécnica do Rio de Janeiro e a de Minas, de Ouro Preto. Esse fenômeno de "cogumelagem" de escolas superiores para as carreiras liberais, e a repartição geográfica, muito desigual, desses estabelecimentos que, com raras exceções (A Escola de Engenharia, de Juiz de Fora, em Minas, e a Faculdade de Direito, em Campos, no Estado do Rio), se concentravam no Rio de Janeiro ou se distribuíam pelas capitais dos Estados, bastariam para provar a persistência da mentalidade criada no tempo do Império, e que se formou e se desenvolveu à sombra das velhas faculdades do país. (AZEVEDO, 1971, p.643).
} 


\subsection{A Reforma Francisco Campos}

O surgimento das Universidades no Brasil se deu por ocasião da Reforma Francisco Campos, no início da década de 1930, no período do Governo Provisório. Francisco Campos foi Ministro da Educação e da Saúde Pública e a reforma que levou seu nome realizou-se com a criação do Conselho Nacional de Educação, a organização do ensino superior, a organização do ensino secundário e a organização do ensino comercial. A efetivação dessa reforma aconteceu, portanto, por meio de uma série de decretos.

Embora o surgimento do ensino superior tenha ocorrido em 1808, quando a família real veio para o Brasil, somente com a reforma de Francisco Campos é que se pode constatar a presença da universidade, sendo esta, na maioria dos casos, uma reunião de cursos superiores que já existiam, justificando o que Azevedo (1971) já anunciou anteriormente, a ideia de "cogumelagem" de cursos superiores. A criação da primeira universidade, a do Rio de Janeiro, se dá devido à agregação dos cursos de Direito, Medicina e da Escola Politécnica, pelo Decreto ${ }^{0}$. 14.343, de 7 de dezembro de 1920.

O Decreto $n^{\circ} .19 .851$, de 11 de abril de 1931, instituiu o regime universitário e fixou os seus fins no Brasil. Em síntese, esse decreto organiza a vida da universidade, o que até então não havia acontecido na educação brasileira. Prevê a organização da administração, a criação de órgãos e funções como Reitoria, Conselho Universitário, Assembleia Universitária e a Direção de cada escola.

Quanto à questão da autonomia, Romanelli aponta uma

(...) flagrante contradição com a descentralização interna. A dependência administrativo-burocrática de cada escola em relação ao Ministério da Educação, a cujo titular competia nomear até os membros dos Conselhos Técnico-Administrativos, denunciava uma tendência acentuadamente centralizadora (...) (ROMANELLI, 1984, p.134).

Temos, assim a visão de uma universidade baseada nos princípios da própria realidade política que o país vivia naquele momento, quando a herança patriarcal e o domínio da sociedade por uma via autoritária eram comuns no cotidiano dos brasileiros.

\subsection{A Reforma Universitária de 1968}

O primeiro momento da expansão da Educação Superior no Brasil data da década de 1960, principalmente por ocasião da elaboração da Lei da Reforma Universitária, de número 5.540, em 1968. Era um momento em que o país se debruçava sobre o desenvolvimento da industrialização, mas, ao mesmo tempo, vivia sob as normas do Regime Militar. Sendo assim, a Reforma Universitária se fez num espaço de disputas de forças internas, tanto no campo da política, da cultura, como também no campo da economia. Tal realidade se caracterizou como um momento próprio de crise do mundo capitalista que se refletia na realidade brasileira.

O modelo arcaico do Ensino Superior não conseguia dar conta dos anseios das classes sociais que detinham o poder naquele momento. Assim, o país buscou soluções em um novo modelo de universidade, fundado nos princípios da racionalidade moderna e do mundo industrializado.

Jesine (2006) sustenta essas inferências dizendo que

isso significava romper com as próprias estruturas sociais arcaicas, por cujo meio mantinham sob controle o poder econômico, cultural e político. Neste sentido, a reformulação da universidade redefiniu-se como problema político, pois não bastava acreditar na racionalidade burguesa e aplicar soluções técnicas para problemas estruturais (JESINE, 2006, p.55).

O modelo de Ensino Superior que se implantou a partir da década de 1960 foi o que mais se aproximou dos interesses do norte da América; o país estabeleceu o convênio MEC-USAID, que se tratava de um acordo de cooperação, e recebeu apoio técnico para a reformulação de seu sistema de educação. Para a elaboração da Lei da Reforma Universitária foi instituído um Grupo de Trabalho ${ }^{7}$, com a publicação de um decreto do Presidente da República Marechal Arthur da Costa e Silva. O decreto estabelecia o prazo de 30 dias para que o grupo concluísse os estudos sobre a Reforma Universitária ${ }^{8}$. Saviani (1997, p. 21) diz que

\footnotetext{
${ }^{7}$ Segundo Saviani (1997, p. 22), o Grupo de Trabalho ficou assim constituído: Fernando Bastos de Ávila, Fernando Ribeiro do Val, João Lira Filho, João Paulo dos Reis Veloso, Newton Sucupira, Roque Spencer Maciel de Barros e Valnir Chagas. Posteriormente o deputado Haroldo Leon Peres fez parte desse grupo.

8 "Na esteira dos Acordos MEC-USAID foi constituído um grupo de trabalho denominado Equipe de Assessoria ao Planejamento do Ensino Superior (Eapes). Tal equipe também produziu um documento, concluído em 1968, que continha análises sobre a educação brasileira e proposições acerca da
} 
esses estudos tinham por objetivo garantir a "eficiência, modernização e flexibilidade administrativa" da universidade brasileira.

Após algumas emendas ao projeto enviado pelo executivo, o Congresso aprovou o texto elaborado pela comissão e enviou-o para o Presidente da República, que em 28 de novembro de 1968 sancionou a Lei 5.540, da Reforma Universitária, com alguns vetos. Posteriormente foi aprovado o Decreto-lei 464, de 11 de fevereiro de 1969, que estabelece normas complementares à Lei 5.540, e dá outras providências.

O processo de elaboração da Lei da Reforma Universitária não contou com a participação dos segmentos da população mais interessada no ensino superior, principalmente a dos estudantes. Saviani (1997, p. 22) afirma que apesar dos esforços do governo para obter a participação oficial dos estudantes, estes se recusaram a participar. A não participação dos estudantes na elaboração da Reforma Universitária se deu porque, naquele contexto, eles foram os únicos a resistirem contra o regime militar.

Sendo assim, a primeira etapa da expansão do ensino superior se deu com a criação das instituições isoladas, ou seja, a iniciativa privada e os municípios participaram do crescimento no número de instituições brasileiras entre as décadas de 1960 e 1970.

Apesar de recomendar que, no âmbito do ensino superior, os recursos financeiros fossem empregados nas universidades oficiais, o Grupo de trabalho Eapes propôs a criação de universidades particulares com ajuda do governo, desde que essas instituições cumprissem a exigência de assegurar vagas a alunos pobres. Germano (2000, p. 124) estabelece a seguinte reflexão: "Embora recomende que a escola privada deva lutar 'pela sobrevivência', abre uma possibilidade de esta receber auxílios do governo, visando assegurar nelas vagas para os alunos pobres".

A Reforma Universitária patrocinada pelo regime militar, segundo Jesine (2006),

representou elemento de consenso e de dominação entre as forças do estado intervencionista e a luta de movimentos advindos da sociedade civil e do inte-

reforma universitária. O Relatório partia do pressuposto de que a educação era essencial ao desenvolvimento econômico da sociedade e sugeria a adoção de medidas já comentadas anteriormente, como: sistema de créditos, organização departamental, ciclo básico e ciclo profissional, etc. Ao lado disso, concedia também grande ênfase à privatização do ensino. Esta seria uma forma de expandir as oportunidades educacionais, à medida que as escolas privadas completassem a ação do Estado no campo educacional". (GERMANO, 2000, p.123). rior da própria universidade, de modo que incorpora, embora de forma desfigurada, experiências e demandas anteriores. As recomendações dos assessores do Acordo MEC-USAID, do Consultor Atcon, e da Comissão Especial presidida pelo General Meira Mattos, destacavam vínculo direto entre educação e mercado de trabalho, sob a concepção da "teoria do capital humano ${ }^{9}(. .$.$) " (JESINE, 2006, p. 59).$

No âmbito político a Reforma Universitária aconteceu mais por uma reação conservadora contra as reivindicações estudantis e da sociedade civil, uma vez que a sociedade e os representantes dos estudantes não puderam participar da elaboração da lei. Romanelli (1984) afirma que

a racionalização, a eficiência e a produtividade tornam-se valores absolutos: têm validade em si e por se mesmos. A racionalidade técnica procura sobrepor-se a qualquer opção de ordem política e a neutralizar o processo de inovação de qualquer ingerência de caráter ideológico. Essa é uma opção obviamente ilusória, pois que a técnica não ocorre no vazio, mas num determinado contexto histórico-político-econômico. A pretensa neutralidade técnica é uma farsa que busca camuflar, com a racionalidade das decisões técnicas, o fortalecimento de uma determinada estrutura de poder que procura, sob várias formas, substituir a participação social pela decisão de poucos. (ROMANELLI, 1984, p. 231).

Portanto, a primeira etapa da expansão se deu no momento em que o país realizava parcerias internacionais para sustentar o desenvolvimento e o progresso, que eram metas claras do novo regime. $\mathrm{O}$ país incentivou o trabalho nas indústrias e estimulou a saída do homem do campo, provocando o crescimento desordenado das cidades.

Na década de 1960, por ocasião da Reforma, a universidade adotou o modelo da modernização, tornando complexa a sua estrutura administrativa e camuflando uma visão conservadora e tecnocrática. Como comenta Jesine (2006, p. 61), ocorreu o distanciamento entre planejamento e execução, bem como entre teoria e prática, e a ideia principal foi a sustentação do rendimento, da eficiência e da produtividade. Todas as ações eram sustentadas pelo ideal norte-americano.

\footnotetext{
${ }^{9}$ Segundo Jesine (2006, p. 59), a teoria do capital humano é uma teoria (Theodor Schultz, 1973) que se desenvolve nos EUA e Inglaterra nos anos de 60 e no Brasil nos anos 70, no contexto das teorias do desenvolvimento após a II Guerra Mundial, em que o capital humano passa a ser o elemento básico.
} 


\section{A política contemporânea e a gestão da Educação Superior}

\subsection{Da LDB ao PNE: a expansão da iniciativa privada}

Para tratar das mudanças na política de Educação Superior nos últimos dez anos, tomaremos a data da publicação da Lei de Diretrizes e Bases da Educação Nacional - LDB -, de número 9.394, de 20 de dezembro de 1996, como marco para nossa análise, início a um novo momento de expansão. Nesse período temos que considerar os dois mandatos de Fernando Henrique Cardoso e os mandatos de Luís Inácio Lula da Silva, momentos em que tivemos algumas mudanças na Educação Superior. Ao mesmo tempo em que se apregoou a necessidade da expansão e busca da qualidade da educação, percebeu-se que existe uma grande crise que assola a Educação Superior no Brasil: a chegada das massas populares nos bancos universitários em contraponto com o discurso da qualidade de ensino.

A população da Educação Superior teve crescimento assustador durante a segunda metade do século XX. Delors (2001, p. 140) aponta que na década de 1970 a população mundial de tal segmento de ensino era de 28 milhões de estudantes, no final do mesmo século esse público passou para mais de 70 milhões. No entanto, o autor ainda pontua que há desigualdades fortes em muitos países, e há dificuldades para estabelecer equiparação entre os países pobres e países ricos.

No Brasil, na década de 1990, a Educação Superior atingiu marcas importantes, principalmente no período após a publicação da LDB n ${ }^{\circ}$ 9.394/96. Evidencia-se a criação dos Centros Universitários; a autonomia das Universidades; a ampliação das vagas nas instituições privadas de Educação Superior; a criação dos Institutos Superiores de Educação, como local para a formação de professores da Educação Básica e a exigência de que até 2007 os professores da Educação Básica deveriam ter formação superior; a criação dos sistemas de avaliação da Educação Superior; o Provão $0^{10}$; o $\operatorname{SINAES}^{11}$; o ENADE ${ }^{12}$, etc. Contudo, foi no início da primeira década do século XXI que houve a expansão mais significativa das

\footnotetext{
${ }^{10}$ Programa de avaliação da Educação Superior criado pelo governo de Fernando Henrique Cardoso.

${ }^{11}$ Sistema Nacional de Avaliação da Educação Superior

${ }^{12}$ ENADE - Exame Nacional de Desempenho de Estudantes.
}

instituições de Educação Superior ${ }^{13}$.

Outro elemento importante é que a Lei de 1996 provocou uma corrida de profissionais que já atuavam na Educação Básica, bem como em outros segmentos, em busca de formação na Educação Superior. Os dados do Ministério da Educação apontam para um rápido crescimento das instituições privadas de Educação Superior, fato que veio a modificar de forma significativa a educação brasileira. O setor privado foi responsável pelo maior crescimento na Educação Superior. Eunice R. Durham (2005) mostra os índices de crescimento da iniciativa privada e informa que a participação deste setor (privado), que oscilava em torno de $60 \%$ entre 1980 e 1998, atingiu 69\% em 2001, com o crescimento de $115 \%$ no total das matrículas. Também, como na década de 1970, o setor público cresceu muito menos, $36 \%$. No conjunto do sistema, sua participação caiu de 41,6\% em 1994 para 31\% em 2001. Essa expansão da Educação Superior ocorreu em todas as regiões do país, com exceção do Nordeste (DURHAM, 2005, p. 230).

Os dados da tabela 1 justificam os argumentos de Durham (2005) e Delors (2001) sobre a expansão das instituições de Educação Superior no Brasil, que, de certa forma, se caracteriza pela rapidez do crescimento, pois, em menos de dez anos, saímos de 900 IES em 1997, para 2.398 em 2006. O índice pode não ser significativo pela porcentagem de alunos que frequentam a Educação Superior, se comparados com o total da população, mas é significativo o percentual do crescimento a cada ano. Sousa (2006, p. 145) aponta que a "taxa de escolarização universitária bruta" dos brasileiros matriculados no ensino superior gira em torno dos $15 \%$. Se considerarmos a população de faixa etária entre 20 e 24 anos, o percentual de alunos matriculados será de $9 \%{ }^{14}$.

\footnotetext{
${ }^{13}$ Em artigo publicado em 1998, Carlos R. Jamil Cury já apontava que um dos avanços significativos da LDB 9.394/96 foi a Flexibilidade. Diminuem os controles cartoriais, a burocracia pode tornar-se bem mais reduzida. (CURY, 1998, p. 75).

${ }^{14}$ A taxa de escolarização bruta de outros países é a seguinte: Argentina (40\%), Uruguai (30\%), Chile (20,6\%), Venezuela (26\%) e Bolívia $(20,6 \%)$. (SOUSA, 2006, p. 145).
} 
Tabela 1 - Total de Instituições de Educação Superior por Ano

\begin{tabular}{l|l|l|l|l|l|l|l|l|l|l}
\hline 1997 & 1998 & 1999 & 2000 & 2001 & 2002 & 2003 & 2004 & 2005 & 2006 & 2007 \\
\hline 900 & 973 & 1.097 & 1.180 & 1.391 & 1.637 & 1.859 & 2.013 & 2.165 & 2.270 & 2.281 \\
\hline
\end{tabular}

Fonte Mec/Inep.

Na década de 1990, a universidade brasileira já era alvo de críticas e alguns educadores já anunciavam a necessidade de adequar-se a um novo modelo de formação de profissionais. Com o crescimento das tendências de privatização do mercado mundial da época, foi se observando a necessidade das instituições brasileiras adotarem o modelo semelhante ${ }^{15}$. Em 1994, em artigo sobre a Educação Superior nos anos 1990, Paiva e Warde (1994) já indicavam a tendência mundial da privatização da Educação Superior. Apontavam para a crise pela qual a educação passava, e a solução ficava cada vez mais distante, uma vez que a economia não sustentava as condições para as mudanças necessárias.

Sobre a mesa para debate não está apenas o chamamento ao setor privado para que se expanda e funcione como empresa lucrativa sem subsídio governamental, ampliando e diversificando a oferta de educação superior, mas a maior produtividade $\mathrm{e}$ eficiência do sistema público existente. (PAIVA; WARDE, 1994, p. 18).

As autoras citadas já anunciavam a grande crise pela qual a universidade passava e justificavam a necessidade da expansão da Educação Superior por meio da iniciativa privada. Paiva e Warde (1994, p. 19) falavam que estamos diante de um avanço de posições favoráveis a uma redistribuição de responsabilidades que empurram no sentido do regionalismo $e$ do localismo. Por um lado, é o que de fato aconteceu, porquanto há faculdades nas localidades mais longínquas do país; cada região está se preocupando em atender os estudantes em potencial, facilitando-lhes o acesso à Educação Superior. Por outro lado, nos últimos dez anos, observa-se o crescimento das grandes instituições de ensino. A redistribuição de responsabilidades, conforme colocado, muitas vezes não ocorreu. Na disputa pelo aluno, as grandes redes de Educação Superior são capazes de oferecer melhores condições para o pagamento das mensalidades, fazendo com que cresçam com mais rapidez.

\footnotetext{
${ }^{15}$ Em 1999, cerca de 75\% das 873 instituições de Educação Superior já pertenciam à iniciativa privada. (RISTOFF, 1999, p. 187).
}

Tabela 2 - Total de Instituições de Educação Superior por Organização Acadêmica

\begin{tabular}{l|c}
\hline & 2.007 \\
\hline Faculdades Integradas & 126 \\
\hline Faculdades, Escolas e Institutos & 1.648 \\
\hline Centros Universitários & 120 \\
\hline Universidades & 183 \\
\hline Total & 2.281 \\
\hline & Fonte Mec/Inep.
\end{tabular}

O discurso que sustentou tais posições foi o da democratização das universidades brasileiras, principalmente o acesso à Educação Superior. A justificativa se fundava na abertura política e nas mudanças da economia, tanto mundial como local. Porém, já havia um modelo previamente pensado para tais mudanças. No que concerne ao papel das universidades, tratava-se de uma nova proposta de organização institucional:

Tudo indica, pois, que estamos diante de um movimento que vai na direção contrária ao modelo humboldtiano de entrelaçamento entre ensino e pesquisa. O modelo americano de Educação Superior de massa com cobertura tendencial universal, por meio de instituições públicas e privadas dedicadas fundamentalmente ao ensino e universidades de elite destinadas a formar as camadas dirigentes por intermédio de cursos que combinam a formação profissional com uma ampla base geral e humanística (modelo Chicago) e nas quais também se realiza a pesquisa realmente importante e bem financiada, parece se espalhar pelo mundo. (PAIVA; WARDE, 1994, p. 35).

Por um lado, o modelo universitário fundado nos princípios humboldtianos ${ }^{16}$ estava sendo questionado, seus defensores procuravam associar o ensino

\footnotetext{
${ }^{16}$ Wilhelm Von Humboldt (1767 - 1835) iniciou seus estudos universitários em 1787 na Universidade de Frankfurt, transferindo-se para a Universidade Reformista de Göttingen, a fim de estudar direito e filologia clássica. Seus estudos foram influenciados pelo pensamento de Kant, pelas leituras da Antiguidade clássica e pelas idéias de Friedrich August Wolf sobre a filologia e a educação. Fez parte do círculo de Weimar, tornando-se amigo de Goethe e Schiller. Segundo Humboldt, experiência significa levar continuamente as observações do homem sobre o mundo e a vida para a vida mental interior, que é o centro da aprendizagem. Aprender é nada mais do que "correspondência contínua entre o nosso modo de ser e o nosso modo de julgar", isto é, nossa existência na práxis e na teoria (PALMER, 2005, p. 104).
} 
e a pesquisa; e, por outro, a crítica era feita aos que pretendiam buscar um novo modelo, o americano. $\mathrm{O}$ contexto da Educação Superior, nos anos de 1990, se traduziu pela crise de sua identidade, ou seja, a necessidade de encontrar o seu papel no cenário mundial. $\mathrm{O}$ que se adotou foi o comprometimento ao modelo americano e o grande incentivo para a criação de universidades privadas. Está aí o motivo do crescimento do número de instituições, porém não sabemos se haverá alunos para sustentá-las dentro de mais algum tempo. Pode-se afirmar que estamos chegando ao momento que aponta para a redução das matrículas na Educação Superior?

Em 2005, o setor privado absorve mais de 67\% das matrículas e abrange $83 \%$ das instituições de Educação Superior (CASTRO, 2005, p. 241). É possível identificar dois caminhos para a Educação Superior privada, sendo que o primeiro deles é o de que a iniciativa privada adote uma postura de valorização das ações acadêmicas, da autonomia do trabalho docente, e a ampliação das estruturas para o ensino e o investimento na pesquisa científica como fundamento de todo trabalho desenvolvido. O outro caminho é o da busca do lucro como principal meta da existência da Educação Superior; daí, então, as dificuldades no investimento das ações acadêmicas.

Um dos grandes problemas da Educação Superior, tanto pública como privada, é que parte significativa das vagas oferecidas fica ociosa e o governo tem tentado criar timidamente programas especiais de financiamento para preenchimento de tais vagas ${ }^{17}$. Porém, sabe-se que há instituições que estão prestes a fechar as portas por não conseguirem lidar com as vagas ociosas. $\mathrm{O}$ fator econômico vem trazer um novo momento na vida das instituições de Educação Superior, o que caracteriza o estabelecimento de uma crise nesse segmento da educação.

O Plano Nacional de Educação - PNE, aprovado pela Lei $\mathrm{n}^{\circ}$. 10.172, de 09 de janeiro de 2001, estabelece em suas metas que até o final desta década o país deverá prover vagas para pelo menos $30 \%$ da população da faixa etária de 18 a 24 anos.

\footnotetext{
${ }^{17}$ Destaca-se, ainda, o Programa Universidade para Todos, que busca equilibrar a precária situação da maioria das instituições de educação superior privada (setor com $35,7 \%$ de vagas ociosas contra $5 \%$ do setor público) por meio de financiamento, a alunos carentes, de vagas em universidades privadas em troca de isenção fiscal. Tal fato, ínfimo em relação ao que expusemos até então, já mostra os fundamentos culturais que embasam as orientações políticas da reforma mercantil da instituição universitária. O Programa Universidade para todos é um simulacro, que busca atender a uma demanda social por meio de uma política econômica (SILVA JUNIOR, 2005, p. 63).
}

Desde a LDB de 1996 o país vem ampliando suas vagas por meio da abertura de cursos sequenciais, abertura de ensino a distância, autonomia para que as Universidades abram novos cursos, e ampliação da rede de ensino da iniciativa privada. Tais iniciativas garantiram a expansão da Educação Superior no Brasil, porém são insuficientes para que as metas colocadas pela LDB e pelo PNE sejam atingidas.

\subsection{Da Gestão da Educação Superior}

Com a publicação da LDB de 1996 o legislador garantiu a mudança estrutural na Educação Superior, o que impulsionou o crescimento do setor privado e, timidamente, do setor público, sendo que este segundo não consegue dar conta da população que procura os bancos universitários, daí o rápido crescimento das vagas em instituições privadas.

Diante da Lei de 1996 a Educação Superior ficou estruturada em Universidades, Centros Universitários e Faculdades, sendo constituída de cursos sequenciais, de graduação, de pós-graduação e de extensão. Porém, a concepção de instituição de ensino ficou comprometida, quando, na explicitação da finalidade, a pesquisa não figura como uma atividade regular, sistemática e continuada, dotada de mecanismos especificos e institucionalizados. (...) (SAVIANI, 1997. p. 216).

Ao tratar da LDB, Fávero (1998, p. 61) chama a atenção para aspetos já garantidos na Constituição de 1988 e que parecem ficar sacrificados na Lei de 1996, principalmente sobre a questão da autonomia. A autora destaca o artigo 207 da Constituição Federal, que garante a autonomia didático-científica, autonomia do ponto de vista administrativo e autonomia de gestão financeira e patrimonial.

A expansão da universidade pós LDB se dá no momento em que o neoliberalismo se instala no Brasil e, ao mesmo tempo, o Banco Mundial estabelece as diretrizes para que o país seja cumpridor. Fávero (1998, p. 66) comenta que é importante que se construa um projeto alternativo para essa universidade que não se limite a discutir o conteúdo das propostas neoliberais e conservadoras. Ou seja, o momento de expansão e de implantação da LDB de 1996 se dá em meio a uma crise e conflitos sobre os rumos da Educação Superior.

Parafraseando a autora já citada, se em 1998 foi possível identificar o compromisso dos governos de Collor de Mello e FHC com a postura neoliberal, 
falta agora incluir o governo Lula, que também faz parte dessa postura de administração. Os três últimos governos foram reféns do novo conservadorismo político e, como consequência, da sua influência na organização da Educação Superior brasileira.

\section{Considerações}

A história da educação tem mostrado que a preocupação com a formação de professores é pouco significativa para os gestores de políticas públicas da educação no Brasil, revelando que há escolas para cada tipo de classe social. Não há políticas públicas claras e convincentes por parte da União, Estados e Municípios. Os governos ainda não conseguiram aliar escola para todos com a qualidade e competência de ensino, pois como o desenvolvimento da industrialização provocou o êxito rural, a massificação da escola e a chegada das camadas populares nas cadeiras do magistério, ocorreu a desvalorização do professor, não pela massificação, mas por ausência de uma política de formação de professores que pudesse dar conta desse novo público que chegava às escolas de formação de professores. A professora que era de classe social mais abastada acaba abandonando o exercício da docência e quem assume o lugar são os estudantes oriundos de classes menos favorecidas.

As políticas públicas de educação no Brasil não consideram a trajetória da escola e do professor, não valorizam sua inserção numa determinada comunidade com suas características próprias. As políticas estão amarradas a uma forma de educação ditada pelos agentes financeiros internacionais, desconsiderando a natureza própria da escola. Segundo Silva Júnior,

no âmbito do MEC, estabelecem-se todos os parâmetros das práticas escolares em todas as suas dimensões, bem como os parâmetros para a sua avaliação, formulam-se as políticas e avaliações e a autonomia é da escola, onde estão os problemas e a solução. São os problemas criados pelo MEC por desconhecer a historicidade da instituição escolar, proporcionando a esta uma falsa autonomia para encontrar a solução, articulando a comunidade e a sociedade civil (...) (SILVA JUNIOR, 2005, p.45).

Segundo dados do INEP, em 2004 o Brasil contava com 5.977 cursos na área da educação, sendo que 1.437 desses cursos são de Pedagogia e 401 são da modalidade Normal Superior. Quanto aos cursos das licenciaturas, denominados pelo INEP de Formação de Professores de Matérias Específicas (história, geografia, biologia, etc.), o país contava com um total de 3.028. Segundo o próprio MEC, os cursos de formação de professores existentes são insuficientes para atenderem às necessidades das escolas.

O sistema educacional brasileiro vive uma crise que afeta fortemente os cursos de formação de professores: se, por um lado, propaga-se a falta de professores na Educação Básica, por outro, não há incentivo profissional para que os jovens procurem os cursos de licenciaturas para serem professores. Os profissionais da educação são mal remunerados, não têm garantia de aperfeiçoamento de profissional, não são respeitados pela sociedade e não gozam de autonomia em seu espaço de trabalho, que é a sala de aula.

Portanto, não há política clara para os cursos de formação de professores, o sistema educacional vive uma falência generalizada sem perspectiva de melhoria para os próximos anos.

\section{Referências}

AZEVEDO, Fernando. A cultura brasileira. 1971.

ANTUNHA, Heládio César Gonçalves. As origens da Faculdade de Educação. Educação e Sociedade. São Paulo, n.01, 1975.

BRZEZINSKI I. Reformulações curriculares nos onze estados participantes do II Encontro Nacional de reformulação dos cursos de formação do educador. Goiânia, 1996, mimeo.

A formação do professor para o início da escolarização. Goiânia: CCG/SE, 1987.

CASTRO, Maria Helena de Magalhães. Estado e mercado na regulação da educação superior. In: SCHWARTZMAN, Simon; BROCK, Colin. Os desafios da educação no Brasil. Rio de Janeiro: Nova Fronteira, 2005.

COSTA, João Cruz. Contribuição à história das idéias no Brasil. Rio de Janeiro: Civilização Brasileira, 1967.

CUNHA, Luiz Antonio. A universidade temporã. Rio de Janeiro: Francisco Alves, 1986.

CURY, Carlos Jamil. Ideologia e educação brasileira: católicos e liberais. São Paulo: Cortez e Moraes, 1978.

DELORS, Jacques (Coord.). Os quatro pilares da educação. In: Educação: um tesouro a descobrir. São Paulo: Cortez, 2001.

DURHAM. Eunice R. Educação Superior, pública e privada (1808 - 2000). In. SCHWARTZMAN, Simon; BROCK, 
Colin. Os desafios da educação no Brasil. Rio de Janeiro: Nova Fronteira, 2005.

FAORO, Formação do patronato político Brasileiro. Porto Alegre: Ed. Globo, 1958.

FÁVERO, Maria de Lourdes de A. A dimensão histórico-política da nova Lei de Diretrizes e Bases da Educação Superior. In: CATANI, Afrânio Mendes (Org.) Novas perspectivas nas políticas de educação superior na América Latina no Limiar do Século XXI. Campinas, SP: Autores Associados, 1998.

FIGUEIREDO, M. C. M. Modelos de cursos de formação de professores e mudanças em políticas: um estudo sobre o Brasil. In. SCHWARTZMAN, Simom; COLIN, Brock. Os desafios da educação no Brasil. Rio de Janeiro: Nova Fronteira, 2005.

FRANCA, Leonel. O método pedagógico dos jesuítas. Rio de Janeiro: Agir, 1952. Agir, 1960.

Noções de história da filosofia. Rio de Janeiro:

GERMANO, José Willington. Estado militar e educação no Brasil (1964 - 1985). São

Paulo: Cortez, 2000.

GUIRALDELLI Junior, Paulo. Filosofia e história da educação brasileira. Barueri, SP: Manole, 2003.

JEZINE, Edineide. A crise da Universidade e o compromisso social da extensão universitária. João Pessoa: Editora da UFPB, 2006.

LAUWERYS, J. Instalação e desenvolvimento das faculdades de educação. Revista Brasileira de Estudos Pedagógicos. Mec/Inep V. 51, abr./jun., 1969.

LEITE, Serafim. Características da Companhia de Jesus. São Paulo, 1989.

. História da Companhia de Jesus no Brasil. Rio de Janeiro: Civilização Brasileira, 1938 (tomos I e II); Instituto nacional do livro, 1943 (tomos III e IV), 1945 (tomos V e VI), 1949 (tomos VII, VIII e XIX).

Breve história da Companhia de Jesus no Brasil, 1549 - 1760. Braga - Portugal: Livraria A. I., 1993.

MANACORDA, M. A. História da educação da antigüidade aos nossos dias. São Paulo. Cortez, 1989.

NAGLE, J. Educação e sociedade na primeira república. São Paulo: EPU/Edusp, 1976.

PAIM, Antonio. História das idéias filosóficas no Brasil. São Paulo: Grifalbo-Edusp, 1974 (Col. História das idéias no Brasil).

PAIVA, Vanilda; WARDE, Mirian Jorge (Orgs.). Dilemas do ensino superior na América Latina. Campinas, SP: Papius, 1994.
PALMER, Joy A. 50 grande educadores. São Paulo: Contexto, 2005.

RISTOFF, Dilvo Ilvo. Universidade em foco: reflexões sobre a educação superior. Florianópolis: Insular, 1999.

ROMANELLI, Otaíza de Oliveira. História da educação no Brasil. 13. ed. Petrópolis: Vozes, 1984.

SAVIANI, Dermeval. A nova lei da educação. LDB, Trajetória, limites e perspectivas. Campinas, SP: Autores Associados, 1997.

Escola e democracia: teorias da educação, curvatura da vara, onze teses sobre educação e política. São Paulo: Cortez, Autores Associados, 1987.

SCHWARTZMAN, Simon; Colin BROCK. Os desafios da educação no Brasil. Rio de Janeiro: Nova Fronteira, 2005.

SILVA JUNIOR, João dos Reis. Pragmatismo e populismo na educação superior: nos governos FHC e Lula. São Paulo: Xamã, 2005.

SOUSA, José Vieira de. Restrição do público e estímulo à iniciativa privada: tendência histórica no Ensino Superior Brasileiro. In. SILVA, Maria Abadia da.; SILVA, Ronalda Barreto (Orgs.). A idéia de universidade: rumos e desafios. Brasília: Líber Livro Editora, 2006.

SUCUPIRA, Newton. Conteúdo específico da faculdade de educação. Brasília, 1969. Documenta. CFE. No 105. Setembro de 1969.

TANURI, L. M. História da formação de professores. In. Revista Brasileira de Educação, v.14, p.61-88, maio-ago, 2000. 